\title{
The second stage of labour
}

\section{Sanjay Singh*}

Department of Obstetrics and Gynecology, Base Hospital Delhi Cantt and Army College of Medical Sciences, New Delhi, India

Received: 30 July 2019

Revised: 07 September 2019

Accepted: 13 September 2019

\section{*Correspondence:}

Dr. Sanjay Singh,

E-mail: drsanjaysingh@gmail.com

Copyright: () the author(s), publisher and licensee Medip Academy. This is an open-access article distributed under the terms of the Creative Commons Attribution Non-Commercial License, which permits unrestricted non-commercial use, distribution, and reproduction in any medium, provided the original work is properly cited.

\begin{abstract}
The second stage of labor begins with full dilatation of cervix and ends with delivery of the fetus. In most of the cases the labor progresses uneventfully, without any need of an active intervention but in few cases complications may occur. With passage of time there has been better understanding about second stage of labor, still there are several grey areas yet to be resolved. This review endeavours to scrutinize a variety of care practices including positions, time and type of pushing, use of epidural analgesia, and perineal support techniques etc and discuss evidence based management of second stage of labor. The review was carried out in the period of 1900-2019 by searching in Pub Med, Embase, Scopus, Google scholar, Web of sciences using relevant key words. Reports, articles, fact sheets and official publications of World health Organization (WHO), Ministry of health and family welfare-Govt of India and various other countries were also reviewed.
\end{abstract}

Keywords: Caesarean section, Fetal pillow, Instrumental delivery, Occipitoposterior position, Odone device, Perineal techniques, Position and pushing during labour, Prolonged second stage, Second stage of labour, Snorkel, Water birth

\section{INTRODUCTION}

The aim of this review is to scrutinize a variety of care practices including positions, time and type of pushing, use of epidural analgesia, and perineal support techniques etc and discuss evidence based management of second stage of labor.

The second stage of labor begins with full dilatation of cervix and ends with delivery of the fetus. The transition from the first stage to second stage of labor is characterized by certain features like, complete dilatation of cervix as evident by vaginal examination, initiation of bearing down effort, crowning of the head, urge to defecate during contraction when head presses the rectum, anal dilation during uterine contraction or early deceleration in fetal heart rate suggesting fetal head compression.
In most of the cases the labor progresses uneventfully, without any need of an active intervention but in few cases complications may occur. ${ }^{1}$ With passage of time there has been better understanding about second stage of labor, still there are certain grey areas yet to be resolved.

\section{DISCUSSION}

\section{Review of literature}

The review was carried out in the period of 1900-2019 by searching in Pub Med, Embase, Scopus, Google scholar, Web of sciences using relevant key words. Reports, articles, fact sheets and official publications of World health Organization (WHO), Ministry of health and family welfare-Govt. of India and various other countries were also reviewed. 


\section{Characteristics of second stage of labour}

Second stage of labor has two phases. The first phase, also known as pelvic phase or phase of descent, is considered as an extension of first stage until pushing starts. This phase starts with full dilatation of the cervix before or in the absence of involuntary expulsive contractions and ends when the head reaches the pelvic floor that initiates the 'bearing down efforts. During this phase rapid descent of the presenting part of the fetus takes place. This phase does not put an extra stress on the fetus and assessment of fetal heart rate may be done at the same frequency as is done in the first stage of labor. As cervical assessment is done 2 hourly, the beginning of this phase is difficult to define accurately. This may lead to misinterpretation of the duration of second stage of labor.

Second phase is perineal phase or phase of expulsion. The second phase starts with the beginning of 'bearing down' efforts and ends with the delivery of the fetus. Normally uteroplacental perfusion and fetal oxygenation start to deteriorate, only when active pushing commences. Thus, undue prolongation of this phase of labor may result in fetal hypoxia.

During second stage, uterine contractions are more frequent, more intense and they last longer. During descent of the presenting part, the resistance offered by the soft tissue and elastic recoil offered by pelvic floor, is overcome by strong uterine contractions and retraction and the bearing down effort of the mother.

\section{Duration of second stage of labour}

The median duration of second stage of labor though may vary widely; it is approximately 50 minutes for nulliparas and about 20 minutes for multiparas. ${ }^{2}$ However, it may become abnormally long in cases of contracted pelvis, with a large fetus, with abnormal fetal position, poor expulsive efforts resulting from conduction analgesia, sedation or maternal exhaustion. In most of the cases where maternal and fetal condition is not compromised, a watchful expectancy may lead to a normal vaginal delivery or a safe instrumental delivery at a lower station. ${ }^{3}$

By the beginning of $20^{\text {th }}$ century, based on perceived concern about maternal and fetal health because of prolonged second stage, the second stage in nulliparas without regional analgesia was limited to 2 hours and with regional analgesia was extended to 3 hours. The same for the multiparas was 1 hour, extended to 2 hours with regional analgesia. The extra one hour grace with regional analgesia was the result of the study done by Cohen (1977), where it was shown that epidural prolongs second stage by one hour. ${ }^{4}$ Menticoglou and coworkers (1995) questioned this fixed prevailing duration of second-stage of labor. ${ }^{3}$ In their study, they concluded that as long as maternal and fetal condition is good, there is no requirement of intervention purely based on the arbitrary limit for the duration of the second stage of labor. However, they observed that with the prolongation of second stage, risk of operative or instrumental deliveries increases progressively.

\section{Prolonged second stage of labour}

Myles and Santolaya (2003) in their study observed that maternal complications do increase because of prolonged second stage like increased operative delivery, perineal trauma, post-partum hemorrhage, chorioamnionitis. ${ }^{5}$ Infants were at increased risk for low 5-minute Apgar score, birth depression, admission to the neonatal intensive care unit, and composite perinatal morbidity. ${ }^{6}$ Continuous support during labour and allowing birthing companion, use of nonsupine position: upright or lateral, avoiding epidural analgesia, delayed pushing in primiparous women with epidural and use of oxytocin for primi under epidural, helps in preventing delay in second stage and avoiding operative vaginal delivery.

Though there is no uniformity in thought process to define prolonged second stage and timing of intervention, ACOG guideline 2014 states that, "Given the available literature, before diagnosing arrest of labor in the second stage and if the maternal and fetal conditions permit, at least 2 hours of pushing in multiparous women and at least 3 hours of pushing in nulliparous women should be allowed. Longer durations may be appropriate on an individualized basis (e.g. with the use of epidural analgesia or with fetal malposition) as long as progress is being documented."7 FIGO guideline 2012 states that, 'Primiparous women should not actively push for more than 2 hours and multiparous women for more than 1 hour, owing to an increased risk of birth asphyxia and maternal infection'. Lack of descent of the presenting part (protracted descent: $<2 \mathrm{~cm} /$ hour for multi and $<1 \mathrm{~cm} /$ hour for primi or arrest of descent: no descent for $>$ one hour) may also indicate obstructed labor and prompt intervention is required in these cases. ${ }^{8,9}$

\section{Position}

Several birthing positions have been in vogue since time immemorial. Women may give birth in upright positions like sitting (on an obstetric chair or stool), standing, kneeling (either on all fours or kneeling up) or squatting (unaided or using a birth cushion or a squatting bar). Some may give birth in supine positions that includes dorsal, lateral (Sims'), semi recumbent or lithotomy position, Trendelenberg's position. The birthing positions are influenced by several factors like setting, caregiver preference, mother's choice or medical intervention. All these birthing positions have got their own advantages and disadvantages as noted in Table 1.

Changing position during second stage has been shown to improve intensity of uterine contractions, reduce the fetal heart rate abnormality and thus reduce the risk of instrumental delivery. ${ }^{13}$ A recent Cochrane review -2017 assessed the effectiveness, benefits and possible 
disadvantages/risks of the different positions for women without epidural, during the second stage of labor and has found it useful. ${ }^{14}$

\section{Pushing}

During second stage of labor the presenting part of the fetus descends down and compresses both bladder and the rectum. This initiates a reflex that causes a strong urge to 'bear down' or 'push'. The combination of the bearing down effort (through the abdominal and respiratory muscles) and involuntary uterine contractions help delivery of the fetus.
The pushing may be of two types: Directed pushing and spontaneous pushing. In directed pushing women take a deep breath at the beginning of a contraction and then hold it and bear down throughout the contraction (valsalva or closed glottis). In spontaneous pushing, women generally push three to five times per contraction, following their own instincts (open glottis). Based on the timing of pushing it may be delayed or immediate. Delayed pushing is the one where women are instructed to avoid pushing until there is an irresistible urge to push or when the presenting part of the fetus has descended to the perineum. Heavy sedation and regional analgesia may reduce the reflex urge to push and may also impair the ability to contract abdominal muscles sufficiently.

Table 1: Advantages and disadvantages of different birthing positions.

\begin{tabular}{|ll|}
\hline Position & $\begin{array}{l}\text { Advantages/disad vantages } \\
\text { Dorsal position } \\
\text { and difficult for the mother, compression of inferior venacava and aorta reduces uteroplacental } \\
\text { perfusion resulting in fetal distress, loss of pelvic mobility and narrower birth canal, loss of gravity } \\
\text { and inefficient uterine contractions }{ }^{10}\end{array}$ \\
\hline $\begin{array}{l}\text { Pelvis is able to expand as baby descends down; gravity facilitates delivery, no venacaval } \\
\text { compression, reduction in second stage of labour by } 6.16 \text { minutes, less pain, fewer episiotomy, } \\
\text { reduction in assisted deliveries, fewer abnormal fetal heart rate patterns: thus has been } \\
\text { recommended by many. However it is associated with more PPH and a possible increase in second } \\
\text { degree perineal tear10 }\end{array}$ \\
\hline $\begin{array}{l}\text { Semi recumbent } \\
\text { position }\end{array}$ & $\begin{array}{l}\text { No venacaval compression but difficult to maintain for longer period and does not increase pelvic } \\
\text { dimensions }\end{array}$ \\
\hline $\begin{array}{l}\text { Kneeling } \\
\text { position }\end{array}$ & $\begin{array}{l}\text { Increases the subpubic space resulting in more anterior space for presenting part, thus puts less } \\
\text { pressure on perineum }\end{array}$ \\
\hline $\begin{array}{l}\text { Squatting } \\
\text { position }\end{array}$ & $\begin{array}{l}\text { Prevents caval compression, increases pelvic outlet diameter and improves maternal bearing down } \\
\text { effort. To make squatting posture comfortable birthing chairs have been used but in trials have been } \\
\text { found causing more PPH and third degree perineal tear. To overcome these complications 'birth } \\
\text { cushion' that gives perineal support and squatting stool (sit down in between contractions and squat } \\
\text { while pushing) has been tried with variable degree of favourable outcome. }\end{array}$ \\
\hline $\begin{array}{l}\text { Hand and knee } \\
\text { position }\end{array}$ & \begin{tabular}{l} 
Useful in delivery of occipito-posterior and occipito-lateral position \\
\hline
\end{tabular} \\
\hline
\end{tabular}

There is no consensus on an ideal strategy to facilitate these expulsive efforts; moreover, there are contradictory results about the influence on the mother and fetus.

Lemos A et al, searched for evidence (Cochrane database review 2017) and identified 8 trials ( 884 women) comparing the types of pushing: spontaneous pushing versus directed pushing with or without epidural analgesia and 13 trials (2879 women) comparing timing of pushing: delayed pushing versus immediate pushing with epidural analgesia. ${ }^{15}$ They concluded that it is not clear whether spontaneous or directed pushing (with or without epidural) results in optimal outcomes for women and babies, based on available evidences. They also could not well-establish the maternal and neonatal benefits and adverse effects of delayed and immediate pushing with epidural.
Delayed pushing with an epidural though shortens the duration of pushing and increases the chance of spontaneous vaginal delivery, it increases the duration of second stage and doubles the risk of low umbilical cord $\mathrm{pH}$. However, they didn't find any difference between delayed and immediate pushing in terms of caesarean and instrumental deliveries, perineal laceration and episiotomy, or other neonatal outcomes (admission to neonatal intensive care, five-minute APGAR score less than seven, and labor room resuscitation). Moreover, adverse effects related to maternal pelvic floor were also not found to be very clear. Therefore, in the absence of strong evidence supporting any specific method or timing of pushing, they suggest that decisions should be guided by the woman's comfort and preference and the clinical scenario. They further, recommend well-designed RCTs, addressing clinically important maternal and neonatal 
outcomes, to add evidence-based information to the current knowledge.

\section{Fundal pressure}

The recent Cochrane review (2017) assessed nine randomized controlled trials (RCTs) involving 3948 women (search date 30 November 2016). Five studies (including 3057 women) analyzed manual fundal pressure versus no fundal pressure and four studies (including 891 women) analyzed at fundal pressure applied using an inflatable belt. Evidences from these RCTs were not robust enough to show whether manual fundal pressure or fundal pressure by inflatable belt are effective ways of shortening the pushing stage of labour and avoiding instrumental births, and whether the techniques are safe. So currently, existing evidences do not support the use of fundal pressure by any method in the second stage of labour. ${ }^{16}$

\section{Water birth}

The perceived benefits of immersion during the first stage of labor are reduced pain, less use of anesthesia and shorter labor. However, existing evidences do not indicate that it improves perinatal outcomes. ${ }^{17}$ The safety of immersion during the second stage of labor has not been established. It has been found to result in reported cases of serious complications in the newborn that includes aspiration, drowning, infection, hyponatremia, and umbilical cord rupture and death. ${ }^{18}$ In a joint opinion paper released by the American Academy of Pediatrics (AAP) and the American College of Obstetricians and Gynecologists (ACOG) concluded that "immersion during the first stage of labor should not prevent or inhibit other elements of care, including appropriate fetal and maternal monitoring. ${ }^{19}$ In contrast, immersion during delivery of the neonate should be considered an experimental procedure that is performed only within the context of an appropriately designed clinical trial".

Cochrane database of systemic reviews 2009, suggests that water immersion during the first stage of labour reduces the use of epidural/spinal analgesia and duration of the first stage of labour. However, there was limited information for other outcomes related to water use during the first and second stages of labor. They did not find any evidence of increased adverse effects to the fetus/neonate or woman from laboring in water or waterbirth. ${ }^{20}$

Both the Royal College of Obstetricians and Gynaecologists and the Royal College of Midwives support laboring in water for healthy women with uncomplicated pregnancies. They agree that the evidence to support underwater birth is less clear but as per them complications are seemingly rare. They feel that if good practice guidelines are followed in relation to infection control, management of cord rupture and strict adherence to eligibility criteria, these complications may be further reduced. ${ }^{21}$
Geissbuehler V et al, and FIGO guidelines on management of the second stage of labor, recommend that the care provider should respect the wishes of a pregnant woman opting for water birth as much as possible without compromising safety. ${ }^{22,23}$

\section{Continuous support during labour}

As per latest Cochrane database review (2017) of 26 trials involving 15,858 women, continuous support during labor has been found to improve outcomes for women and infants. This includes increased spontaneous vaginal birth, shorter duration of labor, decreased cesarean birth, lesser instrumental vaginal birth, less use of any analgesia including use of regional analgesia, low five-minute Apgar score and negative feelings about childbirth experiences. No evidence of harms of continuous labor support was found in the review. ${ }^{24}$ The Govt. of India (2016) and WHO (2002) promote labor companionship as a core element of care for improving maternal and infant health. A close female relative or the husband of the woman may be involved as a birthing companion.

\section{Epidural analgesia and second stage}

Epidural analgesia is the most effective method for pain relief during labor that involves injection of a local anesthetic agent (bupivacaine and fentanyl) into the epidural or peridural space. It is not necessary to wait for the active phase of labor for epidural analgesia, as timing of epidural analgesia does not affect the labor progression. ${ }^{25}$ Several RCTs have proven that timing of epidural placement does not increase the risk of caesarean section, instrumental delivery or fetal malposition. ${ }^{26}$ Epidural analgesia prolongs active phase of labor by one hour. Due to motor blockade induced by the analgesia, there is prolongation of second stage of labor. This is the result of relaxation of the pelvic floor muscle resulting in delay in the rotation of the fetal head and reduced maternal pushing effort because of the motor blockade. Thus, there is an increased need of oxytocin administration and operative vaginal delivery during second stage of labor. ${ }^{27}$

\section{Use of oxytocin in second stage}

Consideration should be given to the use of oxytocin, for nulliparous women if contractions are inadequate at the onset of the second stage. ${ }^{28}$ It would be prudent to rule out cephalopelvic disproportion (CPD) before starting oxytocin in order to prevent uterine rupture. However, O'Driscoll and co-workers, in their study titled active management of labor and cephalopelvic disproportion, showed only $1 \%$ incidence of CPD and no case of uterine rupture in primigravida patients. ${ }^{29}$ Judicious use of oxytocin during second stage has been found to facilitate vaginal delivery and reduce instrumental delivery. Utmost care is required for using oxytocin for 
multiparous women or women with previous caesarean delivery, during second stage of labor.

\section{Episiotomy}

Episiotomy is planned surgical incision on the perineum and posterior vaginal wall, given during second stage of labor to enlarge the vaginal outlet to facilitate delivery.

The incision may be made in the midline from the centre of the fourchette (Median) or may commence from the centre of the fourchette and directed laterally and downwards away from the rectum at an angle of at least $45^{\circ}$ from the midline (mediolateral). Comparing with mediolateral episiotomy, median episiotomy is associated with increased risk of third and fourth degree laceration. ${ }^{30}$ However; it is known for better surgical repair, better healing, less blood loss, less post op pain and less dyspareunia. It has been suggested by Kalis et al, that the resultant suture angle of 40-60 degrees is more important than the incision angle of 45-60 degree, which becomes difficult to achieve over a fully stretched perineum. ${ }^{31}$ An episiotomy performed at 40 degrees results in a postdelivery angle of 22 degrees and as it is closer to midline it is not maximally protective. Special scissors designed to ensure an incision angle of 60 degrees have been shown to be effective in achieving the correct angle. ${ }^{32}$

The use of episiotomy during childbirth was first described in $1742 .{ }^{33}$ By the early 1970 s, episiotomy was a routine practice for all nullipara and most multipara. The proposed benefits were facilitation of delivery, reduction in the incidence of $3^{\text {rd }}$ or $4^{\text {th }}$ degree perineal tears, better surgical healing, less sexual dysfunction, prevention of pelvic floor relaxation resulting in less urinary and fecal/flatal incontinence as well as pelvic organ prolapse and a reduction in fetal asphyxia, cranial trauma and intracranial hemorrhage. However, episiotomy too is associated with complications like pain, increased blood loss, risk of wound hematoma, infection and abscess formation and longer postnatal stay in the hospital while their episiotomy heals. In view of increasing awareness about complications of episiotomy, use of routine episiotomy has been questioned. ${ }^{34}$

The recent Cochrane review of 12 randomized trials (Feb 2017) with 5977 women done by Hong Jiang et al. has found that the evidence does not support a policy of routine episiotomy. In routine episiotomy they found increased risk of severe perineal /vaginal trauma. ${ }^{35}$ Moreover, they did not find a clear difference (increased risk) on blood loss at delivery, new born babies with low APGAR score $(<7)$ at five minutes, perineal infection, women with moderate or severe pain, long term dyspareunia, long term urinary or fecal incontinence and pelvic organ prolapse in restricted episiotomy group comparing routine one. The Society of Obstetricians and Gynaecologists of Canada (SOGC), the Royal College of Obstetricians and Gynecologists (RCOG) and American College of Obstetricians and Gynecologists (ACOG) recommend selective (restrictive) episiotomy only. ${ }^{36-38}$ Thus clinical judgment remains the best guide for use of this procedure.

\section{Perineal techniques during the second stage of labour for reducing perineal trauma}

As per recent Cochrane Database of Systematic Reviews 2017, moderate quality evidence suggests that warm compresses, and perineal massage, may reduce third and fourth degree perineal tears. ${ }^{39}$ However data regarding protective effect of perineal massage is inconclusive. ${ }^{40,41}$ Poor-quality evidence suggests hands-off (or poised) techniques may reduce episiotomy, but this technique had no clear impact on other outcomes. ${ }^{39}$ Data are insufficient to show whether other perineal techniques (e.g. Ritgen's maneuver) result in improved outcomes. ${ }^{39}$ Changing positions during labor, reduction in the use of epidurals, physiological pushing during second stage and use of ventouse helps achieving a 'normal delivery' with an intact perineum. ${ }^{13}$

\section{Fetal heart rate monitoring and fetal distress during second stage of labour}

National Institute for Health and Clinical Excellence (NICE) guidelines for Intrapartum Care recommends intermittent auscultation (IA) of the fetal heart rate immediately after a contraction for at least 1 minute; at least every 5 minutes in the second stage of labour. ${ }^{42}$ However, no robust evidence supports this recommendation. Moreover, from a practical point of view also, listening for one minute at least every five minutes may be difficult for a midwife, who has to provide other care and support to the woman in labor, apart from record keeping. The recently updated 2017 Cochrane Systematic Review of electronic fetal heart rate monitoring showed no reduction in perinatal death or cerebral palsy when compared with continuous cardiotocography (CTG) to IA. It did however demonstrate CTG versus IA leads to higher operative delivery rates, be that by caesarean section or operative vaginal delivery. The only apparent beneficial effect was a $50 \%$ reduction in neonatal seizures. Cochrane review further says that continuous CTG also makes moving and changing positions difficult in labor and women are unable to use a birthing pool. This can impact on women's coping strategies. Thus, it recommends that the women and their doctors need to discuss the woman's individual needs and wishes about monitoring the baby's wellbeing in labour. ${ }^{43}$

Finding of deceleratory changes on CTG monitoring are not unusual during the second stage of labor, which are quite often innocuous. Various decelerations noted during second stage of labor with their interpretations are as appended in Table 2.

Gilstrap LC et al, have found that despite these recommendations, only $30 \%$ of abnormal CTGs will be 
associated with acidosis. Fetal blood $\mathrm{pH}$ thus appears to be useful in detecting truly compromised fetus during $2^{\text {nd }}$ stage of labor for early intervention and avoiding instrumental delivery and caesarean section for rest of the cases with suspicious CTGs but normal $\mathrm{pH}^{45}$ Scalp stimulation test may be a clinical and practical alternative to fetal $\mathrm{pH}$.

Table 2: Various decelerations noted during second stage of labor with their interpretations.

\begin{tabular}{|c|c|c|}
\hline Type of deceleration & Incidence during second stage & Interpretation \\
\hline Early & $\begin{array}{l}16.2 \% \text { in the last } 30 \text { minutes of } \\
\text { labor }^{44}\end{array}$ & $\begin{array}{l}\text { Result of head compression. Does not cause fetal } \\
\text { hypoxia/asphyxia: Normal Fetal pH }\end{array}$ \\
\hline \multicolumn{2}{|c|}{ Isolated fetal bradycardia /tachycardia } & $\begin{array}{l}\text { Worrisome only when associated with loss of variability } \\
\text { or decelerations. Expedite delivery or check for fetal } \\
\text { blood } \mathrm{pH} \text { in early phase of } 2^{\text {nd }} \text { stage }\end{array}$ \\
\hline Variable & $50 \%{ }^{44}$ & $\begin{array}{l}\text { Result of cord compression. Persistent or worsening } \\
\text { variable deceleration may lead to fetal distress and } \\
\text { warrant expedition of delivery }\end{array}$ \\
\hline Late & $\begin{array}{l}4.4 \% \text { in the last } 30 \text { minutes of } \\
\text { labor }^{44}\end{array}$ & $\begin{array}{l}\text { Suggests sign of fetal asphyxia and entails immediate } \\
\text { delivery }\end{array}$ \\
\hline
\end{tabular}

\section{Occipitoposterior position and second stage}

Occipitoposterior position is an important cause of prolonged second stage of labour. Important causes of occipitoposterior position are anthropoid and android pelvis, deflexion of head due to anterior attachment of placenta, high pelvic inclination, brachycephaly and abnormal uterine contraction.

In late labor large caput may obscure the sutures. In such situations feel for unfolded pinna is to be noted as it always points towards the occiput. Late in labor perineum gapes much before head distends it and premature straining can occur. Difficulty is encountered while applying forceps in unrecognized occipitoposterior.

In majority of cases $\left(2 / 3^{\text {rd }}\right)$ with good uterine contractions head adopts the attitude of flexion. In these cases occiput rotates anteriorly through $3 / 8^{\text {th }}$ of a circle (135 degrees) and delivery occurs as in occipito anterior.

When complete anterior rotation fails to occur, labor becomes abnormal. One of the following abnormalities may occur: posterior rotation/malrotation (occipitosacral arrest), short anterior rotation (deep transverse arrest) or non rotation (oblique occipitoposterior arrest/persistent occipitoposterior arrest). Thus partographic monitoring of labor is important. If the CPD is ruled out and contractions are not adequate, augmentation of labor with oxytocin may be done. Those who fail to rotate and deliver, though rotational forceps may be an option, cesarean section is a safer bet.

In posterior rotation vaginal delivery is possible as "face to pubis" with effective uterine contractions, average fetal size and adequate pelvis. With OP position mothers tend to push prematurely due pressures exerted by occiput on the rectum. However, most of these cases require assisted instrumental delivery. Management in cases of short anterior rotation where spontaneous further anterior or posterior rotation with good uterine contractions has not occurred, is either vacuum extraction or manual rotation and forceps delivery or forceps rotation (Kielland's forceps) and delivery, provided the head descends below +2 station in transverse position, there is no fetal distress, fetus is of average size, cervix is fully dilated and pelvis is adequate. If any of these criteria is not met or attempt at vaginal delivery is unsuccessful, caesarean section is done. Forceps rotation requires expertise.

\section{Instrumental delivery and second stage}

Vacuum and forceps are useful tools in conduction of vaginal delivery in cases of prolonged second stage of labor in indicated cases. Selection of the instruments, forceps or vacuum, depends on the preference of the operator in that particular clinical circumstance. ${ }^{46}$ The rotational delivery with Kielland forceps should be performed only by experienced operators. Only restrictive use of episiotomy, based on operator's individual judgment, is supported. ${ }^{46}$

Risk of failure is more under following circumstances and due precautions need to be taken during second stage of labor to decrease it:

- Randomized trials have shown that soft vacuum extractor cups have lower success rates than rigid cups but are less likely to cause maternal and fetal trauma $^{47}$

- Inadequate initial assessment like mid cavity application when head is above the level of ischial spines, occipitoposterior position, big baby $>4000 \mathrm{gm}$ leads to failure 
- Cup not placed properly over the flexion point ${ }^{48}$

- During cup placement, maternal soft tissue entrapment causes cup dislodgement

- If cup is applied over a large caput, there is poor seal causing vacuum leak

- Improper angle of traction

- Poor maternal bearing down adds on to failure rate

- Mid cavity forceps deliveries associated with higher incidence of fetal injuries as compared to outlet or low forceps application ${ }^{49}$

- Insufficient skill in the safe use of forceps

If it is anticipated that attempted instrumental birth may not be successful, it should be considered as a trial and should be undertaken at a place where facility for immediate caesarean section is available. Sequential use of instruments is associated with significant maternal and perinatal morbidity and thus not recommended. ${ }^{50,51}$

One needs to abandon the procedure when there is no evidence of progressive descent with moderate traction during each contraction or when delivery is not imminent following 3 contractions of a correctly applied instrument by an experienced operator.

Forceps and vacuum extraction are associated with different risks and benefits. Risk of failed delivery, cephalhaematoma and retinal hemorrhage is more common with vacuum extraction. However, vacuum delivery is less likely to be associated with significant maternal perineal and vaginal trauma.

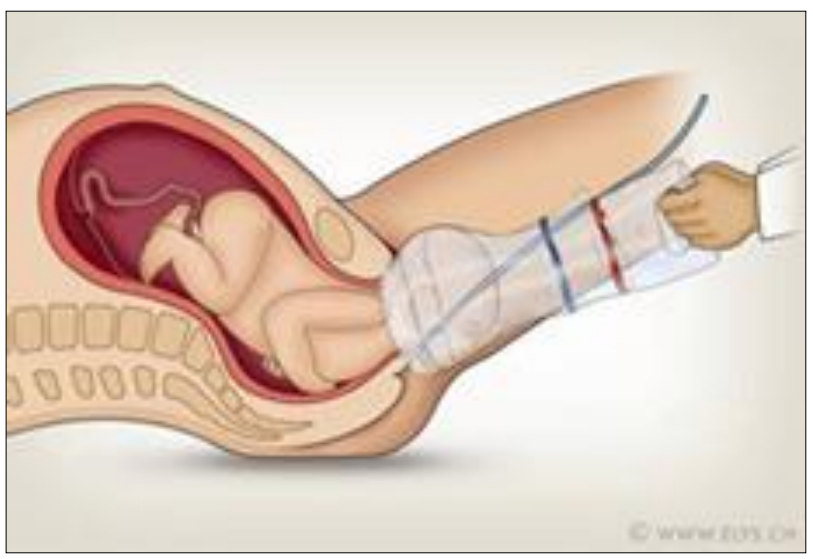

Figure 1: Odon device.

Odon device (Figure 1) is a new low-cost device for delivery of the fetus during prolonged second stage labor. It has already been approved and has been considered promising by FIGO and WHO. This innovative device is safer and easier to apply (with the help of an inserter) than forceps/vacuum extractor and a safe alternative to some caesarean sections especially in a resource poor setting. This consists of a plastic sleeve that is inflated around the baby's head and is used to gently pull out the head of the fetus from the birth canal. ${ }^{52}$

\section{Caesarean section in second stage of labour}

Caesarean sections (CS) during the second stage are increasing. ${ }^{53}$ Compared to CS during first stage of labour $\mathrm{CS}$ at full dilatation is associated with more risk of intraoperative trauma, increased rates of haemorrhage, extension of uterine incision, more NICU admissions and higher risk of perinatal asphyxia. ${ }^{54}$

Disengagement of the impacted fetal head from the pelvic cavity is a challenge to obstetricians. Several techniques have been described in the literature that includes 'push method', the reverse breech extraction or 'pull' method, and Patwardhan's method. Skill and experience of the surgeon guides him to select one of these methods.

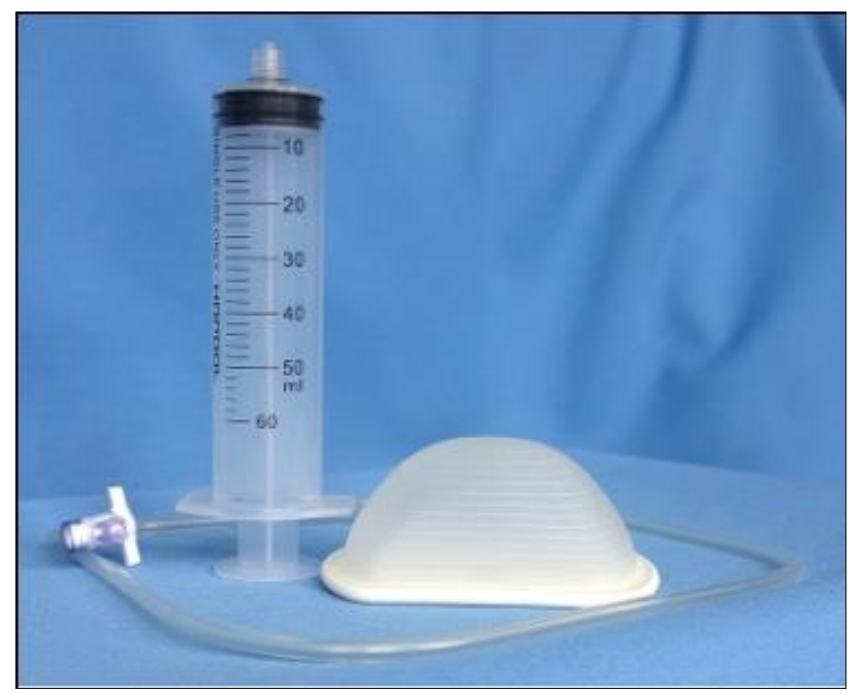

Figure 2: Fetal pillow.

Several innovative devices have been described for disimpaction of the deeply engaged fetal head. The Fetal Pillow, invented by Varma $\mathrm{R}$ in 2007, is a soft silicone balloon device that is used to elevate the fetal head when it is deep in the pelvic cavity (Figure 2). After been inserted below the baby's head, it inflates using saline fluid with a syringe only in one direction and elevates the baby's head. ${ }^{55}$

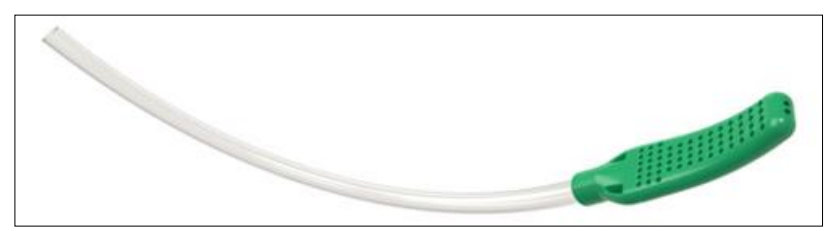

Figure 3: C-Snorkel.

The C-snorkel is a device used for release of well applied fetal head during second stage CS, by alleviating the vacuum that is created between fetal head and maternal tissue. It consists of medical grade polymer curved tube with a flat anatomically curved polymer tip with multiple ventilation points (Figure 3). It is inserted into vagina 
posteriorly, in the hollow of sacrum between posterior vaginal wall and fetal head. This releases the vacuum of well applied fetal head, enabling a less traumatic delivery. ${ }^{54}$

Whereas the theoretical benefits of both devices are promising, and both are being marketed, neither has been demonstrated to be effective in any controlled study with meaningful endpoints. ${ }^{54}$

\section{CONCLUSION}

Second stage of labor has two phases. The first phase is pelvic phase or phase of descent and the second phase is perineal phase or phase of expulsion. Normally uteroplacental perfusion and fetal oxygenation start to deteriorate, only when active pushing commences. As long as maternal and fetal condition is good, and progress of labor is documented, there is no requirement of intervention purely based on the arbitrary limit for the duration of the second stage of labor. Changing position during second stage has been shown to improve intensity of uterine contractions, reduce the fetal heart rate abnormality and thus reduce the risk of instrumental delivery. Adoption of nonsupine position during second stage appears to be superior. In the absence of strong evidence supporting any specific method or timing of pushing, it is suggested that decision of pushing should be guided by the woman's comfort and preference and the clinical scenario. Existing evidences do not support the use of fundal pressure by any method in the second stage of labor. Whereas FIGO (2012) and RCOG (2006) recommend water birth for desirous mother without compromising safety, ACOG (2014) considers this experimental. The Govt. of India (2016) and WHO (2002) promote labor companionship as a core element of care for improving maternal and infant health. Epidural analgesia prolongs active phase and second stage of labor. Thus there is an increased need of oxytocin administration and operative vaginal delivery during second stage of labor. Oxytocin can be used in second stage of labor wherever indicated, with due care especially in muligravida. Only selective (restrictive) episiotomy is recommended and clinical judgment remains the best guide for use of this procedure. Moderate quality evidence suggests that warm compresses may reduce OASIS. Role of perineal massage on prevention of OASIS has been questioned. Poorquality evidence suggests hands-off (or poised) techniques may reduce episiotomy, but this technique had no clear impact on other outcomes. Most of the cases of occipitoposterior presentations are able to deliver vaginally either by rotation to occipitoanterior position during labor or by 'face to pubis' vaginal delivery. The operator should choose the instrument (vacuum or forceps) most appropriate to the clinical circumstances and their level of skill to minimize fetal and maternal injuries. Skill and experience of the surgeon guides him to select a suitable method to disimpact the fetal head during second stage cesarean. Pull technique appears to be relatively superior to push technique.

Funding: No funding sources

Conflict of interest: None declared

Ethical approval: Not required

\section{REFERENCES}

1. Weindling AM. The confidential enquiry into maternal and child health (CEMACH). Arch Dis Childhood. 2003;88:1034-7.

2. Kilpatrick SJ, Laros RK. Characteristics of normal labor. Obstet Gynecol. 1989;74:85.

3. Menticoglou SM, Manning F, Harman C. Perinatal outcome in relation to second stage duration. Am $\mathbf{J}$ Obstet Gynecol. 1995;173:906.

4. Cohen W. Influence of the duration of second stage labor on perinatal outcome and puerperal morbidity. Obstetgynecol. 1977;49:266.

5. Myles TD, Santolaya J. Maternal and neonatal outcomes in patients with a prolonged second stage of labour. Obstet Gynecol. 2003;102(1):52.

6. Allen VM, Baskett TF. Maternal and perinatal outcomes with increasing duration of the second stage of labor. Obstet Gynecol. 2009;113(6):1248-58.

7. Safe prevention of the primary cesarean delivery. Obstetric Care Consensus No. 1. American College of Obstetricians and Gynecologists. Obstet Gynecol. 2014;123:693-711.

8. FIGO safe Motherhood and Newborn Health (SMNH) Committee, Management of the second stage of labor. Int J Gynecol Obstet. 2012;119:111-6.

9. Le Ray C, Audibert F, Goffinet F, Fraser W. When to stop pushing: effects of duration of second-stage expulsion efforts on maternal and neonatal outcomes in nulliparous women with epidural analgesia. Am J Obstet Gynecol. 2009;201(4):361.e1-361.e7.

10. De Jong PR, Johanson RB, Baxen P, Adrians VD, Van Der Westhuisen S, Jones PW. Randomised trial comparing the upright and supine positions for the second stage of labour. $\mathrm{Br} \mathrm{J}$ Obstet Gynaecol. 1997;104:567-71.

11. Gardosi J, Sylvester S, B-Lynch C. Alternative positions in second stage of labour: a randomised controlled trial. Br J ObstetGynaecol. 1989;96:1290-6.

12. Gardosi J, Sylvester S, B-Lynch C. Randomised, controlled trial of squatting in the second stage of labour. Lancet. 1989:ii:74-7.

13. Siraj N, Johanson R. The second stage of labour. In: Progress in Obstetric Gynnecology. Churchill Livingstone. 2000;14:170-87.

14. Gupta JK, Sood A, Hofmeyr GJ, Vogel JP. Position in the second stage of labour for women without epidural anaesthesia. Cochrane Database Syst YR. 2017;5:ID: CD002006.

15. Lemos A, Amorim M, Dornelas de Andrade A, de Souza AI, Filho JC, Correia JB. Pushing/bearing down methods for the second stage of labour. Cochrane Database Syst Reviews. 2017;3:ID: CD009124. 
16. Hofmeyr G, Vogel JP, Cuthbert A, Singata M. Fundal pressure during the second stage of labour. Cochrane Database Syst Reviews. 2017;3:CD006067.

17. Pinette MG, Wax J, Wilson E. The risks of underwater birth. Am J Obstet Gynecol. 2004;190:1211-5.

18. American College of Obstetricians and Gynecologists. Immersion in water during labor and delivery. Committee Opinion No. 594. Obstet Gynecol. 2014;123:912-5.

19. American Academy of Pediatrics Committee on Fetus and Newborn; American College of Obstetricians and Gynecologists Committee on Obstetric Practice. Immersion in water during labor and delivery. Pediatrics. 2014.

20. Cluett ER, Burns E. Immersion in water in labour and birth. Cochrane Database Syst Reviews. 2009;2:CD000111.

21. Immersion in water during labour and birth. RCOG/Royal College of Midwives Joint Statement No. 1. London, England: Royal College of Obstetricians and Gynaecologists, Royal College of Midwives; 2006.

22. Geissbuehler V, Stein S, Eberhard J. Waterbirths compared with landbirths: an observational study of nine years. J Perinat Med. 2004;32(4):308-14.

23. FIGO Safe Motherhood and Newborn Health (SMNH) Committee, Management of the second stage of labor. Int J Gynecol Obstet. 2012;119:111-6.

24. Bohren MA, Hofmeyr GJ, Sakala C, Fukuzawa RK, Cuthbert A. Continuous support for women during childbirth. Cochrane Database Syst Reviews. 2017;7:CD003766.

25. American College of Obstetricians and Gynaecologists: Obstetrics analgesia and anesthesia. Practice bulletin. Reaffirmed. 2013:36.

26. Sng BL, Leong WL. Early versus late initiation of epidural analgesia for labour. Cochrane Database Syst Review. 2014;10:CD007238.

27. Anim-Somuah M, Smyth RMD, Jones L. Epidural versus non-epidural or no analgesia in labour. Cochrane Database Syst Rev. 2011;12:CD000331.

28. NICE clinical guidelines. Intrapartum care for healthy women and babies. Clinical guideline no: CG190. Published date: December 2014. Last updated: 2017. Available at: nice.org.uk/guidance/cg190.

29. O’Driscoll D, Jackson RJA, Gallagher JT. Active management of labour and cephalopelvic disproportion. J Obstet Gynaecol Br Commonwealth. 1970;77:385-9.

30. Shiono P, Klebanoff MA, Carey JC. Midline episiotomies: more harm than good? Obstet. Gynecol. 1990;75(5):765-70.

31. Kalis V, Landsmanova J, Bednarova B, Karbanova J, Laine K, Rokyta Z. Evaluation of the incision angle of mediolateral episiotomy at 60 degrees. Int J Gynaecol Obstet. 2011;112:220-4.
32. Freeman RM, Hollands HJ, Barron LF, Kapoor DS. Cutting a mediolateral episiotomy at the correct angle: evaluation of a new device, the Episcissors60. Med Devices (Auckl). 2014;7:23-8.

33. Ould F. A treatise on midwifery in three parts. Nelson Connor, Dublin, Ireland. 1742.

34. Harrison RF, Brennan M, North PM, Reed JV, Wickam EA. Is routine episiotomy necessary? Br. Med J (Clin Res Ed). 1984;288(6435):1971-4.

35. Jiang H, XuQian, Carroli G, Garner P. Selective versus routine use of episiotomy for vaginal birth. Cochrane Database Syst Review. 2017;2:ID:CD000081.

36. Joint Policy Statement on Normal Childbirth. No. 221. J Obstet Gynaecol Can. 2008;30(12):1163-5.

37. National Collaborating Centre for Women's and Children's Health. Intrapartum care: care of healthy women and their babies during childbirth. Royal College of Obstetricians and Gynaecologists Press, London, UK. 2007;168-170.

38. American College of Obstetrics and Gynecology. Episiotomy. ACOG Practice Bulletin 71. Obstet. Gynecol. 2006;107:957-62.

39. Aasheim V, Nilsen A, Reinar L, Lukasse M. Perineal techniques during the second stage of labour for reducing perineal trauma. Cochrane Database Syst Reviews. 2017;6:CD006672.

40. Royal College of Obstetrician and Gynaecologists. The management of third and fourth degree perineal tears: Greentop Guideline No. 29. London: RCOG. 2015.

41. The American College of Obstetricians and Gynecologists. Prevention and management of obstetric lacerations at vaginal delivery. Practice Bulletin No. 165: Obstet Gynecol. 2016;128(1):e1-e15.

42. Nice Intrapartum Care: care of healthy women and their babies during childbirth. Guideline Number: 190; 2014. Available at: nice.org.uk/guidance/cg190.

43. Alfirevic Z, Devane D, Gyte GML, Cuthbert A. Continuous cardiotocography (CTG) as a form of electronic fetal monitoring (EFM) for fetal assessment during labour. Cochrane Database Syst Reviews. 2017;2:CD006066.

44. Beard RW, Filshie GM, Knight CA, Roberts GM. The significance of the changes in the continuous fetal heart rate in the first stage of labour. J Obstet Gynaecol Br Commonwealth. 1971;78:865-83.

45. Gilstrap LC, Hauth JC, Hankins GD, Beck AW. Second stage fetal heart abnormalities and type of neonatal acidaemia. Obstet Gynaecol. 1987;70:191-5.

46. Royal College of Obstetricians and Gynaecologists. Green-top Guideline No. 26: Operative vaginal delivery. London: RCOG; 2011.

47. Johanson R, Menon V. Soft versus rigid vacuum extractor cups for assisted vaginal delivery, Cochrane Database Syst Review. 2000.

48. Baskett TF, Fanning CA, Young DC. A prospective observational study of 1000 vacuum assisted deliveries with the Omnicup device. J Obstet Gynecol. 2008;30(7):573. 
49. Bowes WA, Katz VL. Operative vaginal delivery: forceps and vacuum extractor. Curr Prob Obstet Gynecol Fertil. 1994;17:83.

50. Gardella C, Taylor M, Benedetti T. The effect of sequential use of vacuum and forceps for assisted vaginal delivery on neonatal and maternal outcomes. Am J Obstet Gynecol. 2001;185:896.

51. Committee on Practice Bulletins-Obstertrics. ACOG practice bulletin 154. Summary: Operative vaginal delivery. Obstete Gynecol. 2015;126:1118.

52. The World Health Organization Odon Device Research Group. Feasibility and safety study of a new device (Odón device) for assisted vaginal deliveries: study protocol. Repro Health. 2013;10:33.

53. Unterscheider J, McMenamin M, Cullinane F. Rising rates of caesarean deliveries at full cervical dilatation: a concerning trend. Eur J Obstet Gynaecol Reprod Biol. 2011;157:141-4.

54. Vousden N. Caesarean section at full dilatation: incidence, impact and current management. The Obstet Gynaecol. 2014;16:199-205.

55. Singh M, Varma R. Reducing complications associated with a deeply engaged head at caesarean section: a simple instrument. Obstet Gynaecol. 2008;10:38-41.

Cite this article as: Singh $\mathrm{S}$. The second stage of labour. Int J Reprod Contracept Obstet Gynecol 2019;8:4120-9. 